Paper

\title{
Effect of Si Addition on the Soft Magnetic Properties in High Frequency Range for Fe-Ni Alloy Powder
}

\author{
Fumihiro KINO*, Nobuhito CHUJO, Keita KUME, Toshihumi AOYAMA and Masakatsu FUKUDA \\ MITSUBISHI STEEL MFG. CO., LTD., 405 Aza-rokucho, Hirota, Kawahigashi-machi, Aizu-Wakamatsu 969-3471, Japan.
}

Received November 28, 2015; Revised January 19, 2016; Accepted February 23, 2016

\begin{abstract}
Recently, soft magnetic metal powders are widely used for electric components such as inductors. These are required further improvement of magnetic properties. Fe-Ni soft magnetic alloys are called "Permalloy" and are known as high magnetic permeability alloys. In particular, "Permalloy B (JIS)", Fe-45 50Ni, is expected for application of inductors because of high saturation magnetic flux density. We researched the effect of Si addition into "Permalloy B" on the magnetic properties in high frequency range. Powders were prepared by gas atomization process and mixed with resin and lubricant, and then compacted into toroidal shape cores. These cores were heat-treated for hardening resin and release of internal stress by compaction. Effective permeability was measured by LCR meter up to $100 \mathrm{MHz}$ and core loss was measured by B-H analyzer up to $5 \mathrm{MHz}$. As a result, permeability was slightly decreased but core loss was reduced by Si addition. Core loss was also reduced by using finer powders (mean particle diameters are less than $10 \mu \mathrm{m}$ ). Moreover, the permeability increased by the heat treatment of core after compaction. We found the availability of soft magnetic metal powders in high frequency over $3 \mathrm{MHz}$ for using inductors.
\end{abstract}

\section{KEY WORDS}

soft magnetic powder, Fe-Ni alloy, gas atomization, core loss, inductor

\section{Introduction}

Soft magnetic powders are widely used for electric components such as transformers, reactors and inductors. These are required further improvement of magnetic properties for miniaturization, improving performance and efficiency. In the past, soft ferrites have been used in high frequency of over $1 \mathrm{MHz}$ because they have high electrical resistivity. Recently they have been replaced with metallic materials with high magnetic flux density. In particular, metal composite inductors which are built-in coil have been used for mobile devices at $1 \sim 3 \mathrm{MHz}$ in frequency. These are expected to be applied higher frequency range in a few years later.

Fe-Ni alloys called "Permalloy" are known as high magnetic permeability alloys in the soft magnetic alloys ${ }^{1)}$. In particular, "Permalloy B(JIS)", Fe-45 50Ni, is expected for application of inductors because of high saturation magnetic flux density compared with "Permalloy C(JIS)", Fe-79Ni-5Mo. As past research about frequency characteristics of Fe-Ni alloys, Ichinose reported decline of permeability to high frequency was suppressed by small amount of Si addition to Fe-50Ni alloy ${ }^{2)}$. Fukuda et al. reported permeability remained nearly constant until $1 \mathrm{GHz}$ by addition of $\mathrm{Si}$ to $\mathrm{Fe}-50 \mathrm{Ni}$ alloy, and control of particle diameter and filling ratio

* Corresponding Author, E-mail: kino.fumihiro@mitsubishisteel.co.jp of powders ${ }^{3)}$. But these reports were related to permeability, there were little reports about core loss at high frequency over $1 \mathrm{MHz}$. Therefore, we investigated the effect of Si addition to Fe-Ni alloy and control of particle size on the permeability and the core loss in the $\mathrm{MHz}$ range.

\section{Experiment}

\subsection{Effect of Si addition}

For the purpose of increasing electrical resistivity, Fe-48 mass $\%$ $\mathrm{Ni}-\mathrm{X}$ mass\% $\mathrm{Si}(\mathrm{X}=0,1.0,1.5,2.0)$ alloy powders were prepared by gas atomization in Ar atmosphere melting. These powders were sieved less than $75 \mu \mathrm{m}$, then measured mean particle diameters by laser diffractmetry.

3.0 mass $\%$ of silicone resin was added as insulation and binder to $\mathrm{Fe}-\mathrm{Ni}-\mathrm{Si}$ powders, and then 0.5 mass $\%$ of zinc stearate was added as lubricant to them. These powders were compacted into toroidal shape cores by uniaxial press in the size of $21 \mathrm{~mm}$ in outer diameter, $13.5 \mathrm{~mm}$ in inner diameter, and $1.7 \mathrm{~mm}$ in thickness at $980 \sim 1078 \mathrm{MPa}$. The packing fraction of powder was adjusted to be equal control by compaction pressure. Toroidal cores were heat-treated for $1 \mathrm{~h}$ at $150{ }^{\circ} \mathrm{C}$ in the atmosphere to harden the silicone resin. These samples were measured the permeability and the core loss. 
Effective permeability $\mu_{\mathrm{e}}{ }^{\prime}$ was calculated by equation (1) from measuring results of inductance of the toroidal cores with 10 turns in the winding ${ }^{4)}$. These were measured at $1 \sim 100 \mathrm{MHz}$ in the range of frequency by LCR meter 4287A and test fixture 16093A (Agilent Technologies, Inc.).

$$
\mu_{\mathrm{e}}^{\prime}=\frac{\left(\mathrm{L}_{\mathrm{eff}}-\mathrm{L}_{\mathrm{w}}\right) \cdot 1_{\mathrm{m}}}{\mu_{0} \cdot \mathrm{n}^{2} \cdot \mathrm{A}},
$$

where $\mathrm{L}_{\text {eff }}$ is effective inductance of core, $\mathrm{L}_{\mathrm{w}}$ is inductance of coil, $1_{\mathrm{m}}$ is magnetic pass length, $\mu_{0}$ is permeability in vacuum, $\mathrm{n}$ is turn of coil and A is cross sectional area of core.

Samples were wound 20 turns in the primary winding and 10 turns in the secondary winding. Core loss $\mathrm{P}_{\mathrm{c}}$ was measured at $1 \sim 5 \mathrm{MHz}$ in the range of frequency for $0.01 \mathrm{~T}$ in the magnetic flux density by B-H analyzer SY-8218 (Iwatsu Test Instruments, Co.).

\subsection{Effect of mean particle diameter}

Gas atomized powders were classified to $10 \mu \mathrm{m}$ in mean particle diameter by inertial classification. Furthermore, we investigated magnetic properties of cores which consisted of powders less than $10 \mu \mathrm{m}$ in mean particle diameters. We prepared water atomized powders of same composition because it was difficult to obtain the powders less than $10 \mu \mathrm{m}$ by gas atomization. Water atomized powders were classified to $3 \sim 10 \mu \mathrm{m}$ in mean particle diameters, and then prepared toroidal cores at 1225 1421 MPa and measured the magnetic properties.

\subsection{Effect of heat treatment of the magnetic core}

The cores were heat-treated for $1 \mathrm{~h}$ at 400, 600, 700, 750 and $800{ }^{\circ} \mathrm{C}$ in $\mathrm{Ar}$ atmosphere. And then these cores were measured the magnetic properties.

\section{Results}

\subsection{Effect of Si addition}

The chemical compositions and the particle diameters of Fe-48Ni-Si gas atomized powders are shown in Table 1. The compaction pressures and the packing fractions of toroidal cores for gas atomized powders were shown in Table 2. As results of the magnetic measurements, the frequency characteristics of $\mu_{\mathrm{e}}{ }^{\prime}$ and $\mathrm{P}_{\mathrm{c}}$ for the powders are shown in Fig. 1 and Fig. 2, respectively. And the effects of Si addition to Fe-48Ni on $\mu_{\mathrm{e}}{ }^{\prime}$ at $5 \mathrm{MHz}$ and $\mathrm{P}_{\mathrm{c}}$ at $5 \mathrm{MHz}$ for $0.01 \mathrm{~T}$ are shown in Fig. 3 and Fig. 4, respectively. $\mu_{\mathrm{e}}{ }^{\prime}$ was slightly decreased with increasing the amount of $\mathrm{Si}$ addition. $\mathrm{P}_{\mathrm{c}}$ was slightly reduced by $\mathrm{Si}$ addition.

Table 1 The chemical compositions and the particle diameters of Fe$48 \mathrm{Ni}-\mathrm{Si}$ gas atomized powders.

\begin{tabular}{ccccccc}
\hline & $\begin{array}{c}\mathrm{Ni} \\
{[\mathrm{mass} \%]}\end{array}$ & $\begin{array}{c}\mathrm{Si} \\
{[\mathrm{mass} \%]}\end{array}$ & $\begin{array}{c}\mathrm{Fe} \\
{[\mathrm{mass} \%]}\end{array}$ & $\begin{array}{c}\mathrm{D}_{10} \\
{[\mu \mathrm{m}]}\end{array}$ & $\begin{array}{c}\mathrm{D}_{50} \\
{[\mu \mathrm{m}]}\end{array}$ & $\begin{array}{c}\mathrm{D}_{90} \\
{[\mu \mathrm{m}]}\end{array}$ \\
\hline $48 \mathrm{Ni}$ & 47.87 & - & Bal. & 15.6 & 30.5 & 51.1 \\
$48 \mathrm{Ni}-1 \mathrm{Si}$ & 47.93 & 0.97 & Bal. & 13.5 & 30.1 & 51.2 \\
$48 \mathrm{Ni}-1.5 \mathrm{Si}$ & 48.30 & 1.42 & Bal. & 12.2 & 30.0 & 51.8 \\
$48 \mathrm{Ni}-2 \mathrm{Si}$ & 47.70 & 1.86 & Bal. & 14.0 & 30.5 & 50.5 \\
\hline
\end{tabular}

Table 2 The compaction pressures and the packing fractions of toroidal cores for $\mathrm{Fe}-48 \mathrm{Ni}-\mathrm{Si}$ gas atomized powders.

\begin{tabular}{ccc}
\hline & $\begin{array}{c}\text { Compaction pressure } \\
{[\mathrm{MPa}]}\end{array}$ & $\begin{array}{c}\text { Packing fraction } \\
{[\mathrm{vol} \%]}\end{array}$ \\
\hline $48 \mathrm{Ni}$ & 980 & 76.4 \\
$48 \mathrm{Ni}-1 \mathrm{Si}$ & 980 & 74.3 \\
$48 \mathrm{Ni}-1.5 \mathrm{Si}$ & 1078 & 75.0 \\
$48 \mathrm{Ni}-2 \mathrm{Si}$ & 1078 & 75.3 \\
\hline
\end{tabular}

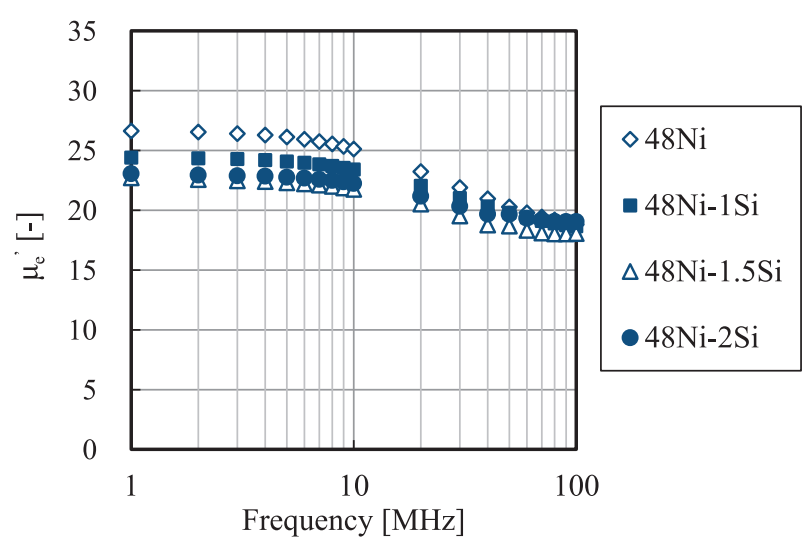

Fig. 1 Frequency characteristics of $\mu_{\mathrm{e}}^{\prime}$ for Fe-48Ni-Si powders.

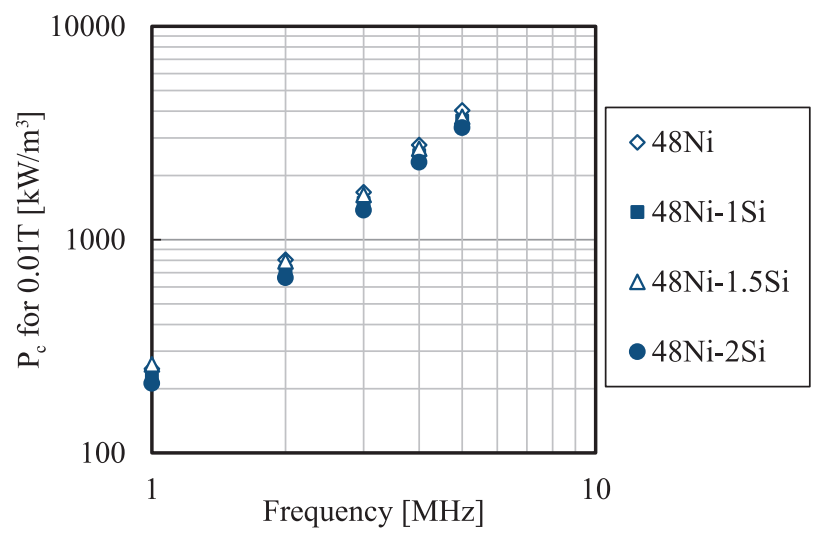

Fig. 2 Frequency characteristics of $\mathrm{P}_{\mathrm{c}}$ for $\mathrm{Fe}-48 \mathrm{Ni}-\mathrm{Si}$ powders.

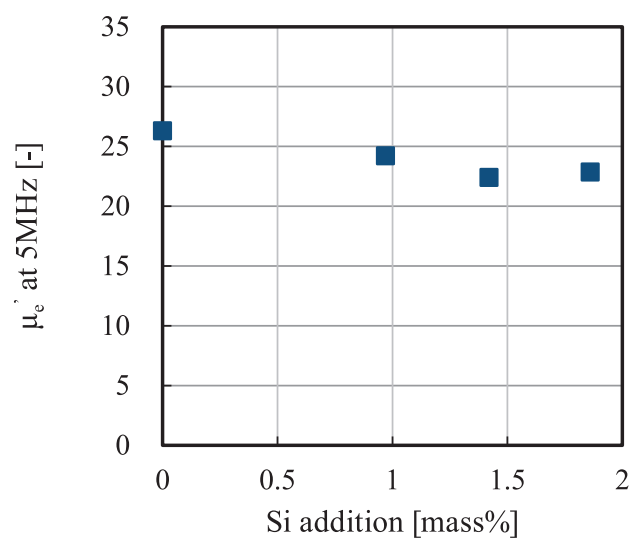

Fig. 3 Effect of Si addition to Fe-48Ni on $\mu_{\mathrm{e}}{ }^{\prime}$ at $5 \mathrm{MHz}$. 


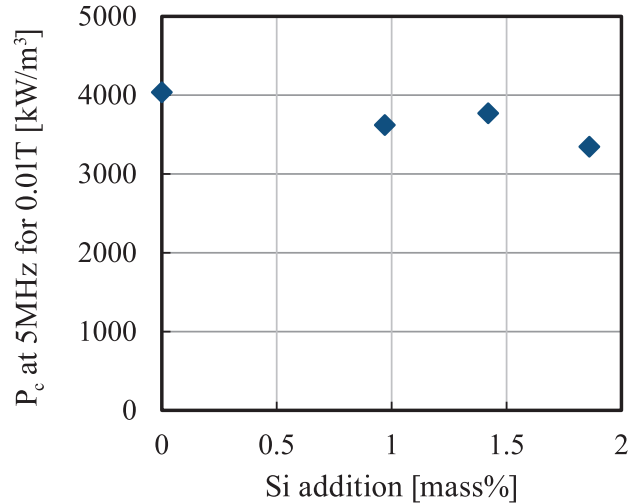

Fig. 4 Effect of $\mathrm{Si}$ addition to $\mathrm{Fe}-48 \mathrm{Ni}$ on $\mathrm{P}_{\mathrm{c}}$ at $5 \mathrm{MHz}$ for $0.01 \mathrm{~T}$.

Table 3 The chemical compositions of Fe-48Ni-1.5 Si gas and water atomized powders.

\begin{tabular}{cccc}
\hline & Ni [mass\%] & Si [mass\%] & Fe [mass\%] \\
\hline Gas Atomized Powders & 48.30 & 1.42 & Bal. \\
Water Atomized Powders & 48.85 & 1.47 & Bal. \\
\hline
\end{tabular}

Table 4 The particle diameters of Fe-48Ni-1.5Si gas atomized powders.

\begin{tabular}{cccc}
\hline & $\mathrm{D}_{10}[\mu \mathrm{m}]$ & $\mathrm{D}_{50}[\mu \mathrm{m}]$ & $\mathrm{D}_{90}[\mu \mathrm{m}]$ \\
\hline $30 \mu \mathrm{m}$ & 12.2 & 30.0 & 51.8 \\
$10 \mu \mathrm{m}$ & 4.9 & 10.2 & 18.1 \\
\hline
\end{tabular}

From these results, there were no significant differences in the range of $1 \sim 2 \% \mathrm{Si}$ addition, so we considered it would not to be expected for drastic improvement of magnetic properties in high frequency by small amount of Si addition.

\subsection{Effect of mean particle diameter}

The chemical compositions of Fe-48Ni-1.5Si gas and water atomized powders are shown in Table 3. The particle diameters of the gas atomized powders are shown in Table 4, and SEM images of each powder are shown in Fig. 5. The compaction pressures and the packing fractions of toroidal cores for gas atomized powders were shown in Table 5. As results of the magnetic measurements, the frequency characteristics of $\mu_{\mathrm{e}}^{\prime}$ and $\mathrm{P}_{\mathrm{c}}$ for each powder are shown in Fig. 6 and Fig. 7, respectively. The frequency characteristics were significant differences in high frequency over $10 \mathrm{MHz} . \mu_{\mathrm{e}}{ }^{\prime}$ at
Table 5 The compaction pressures and the packing fractions of toroidal cores for $48 \mathrm{Ni}-1.5 \mathrm{Si}$ gas atomized powders.

\begin{tabular}{ccc}
\hline & $\begin{array}{c}\text { Compaction pressure } \\
{[\mathrm{MPa}]}\end{array}$ & $\begin{array}{c}\text { Packing fraction } \\
{[\mathrm{vol} \%]}\end{array}$ \\
\hline $30 \mu \mathrm{m}$ & 1078 & 75.0 \\
$10 \mu \mathrm{m}$ & 1127 & 75.6 \\
\hline
\end{tabular}

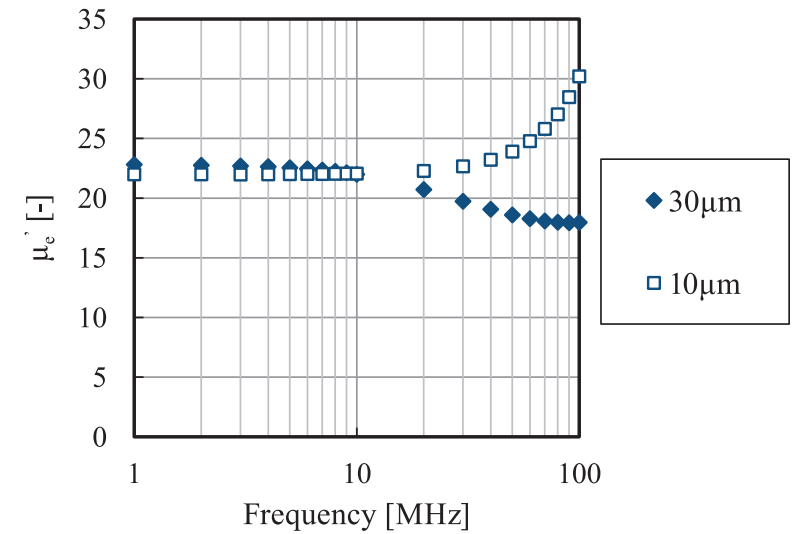

Fig. 6 Frequency characteristics of $\mu_{\mathrm{e}}{ }^{\prime}$ for $48 \mathrm{Ni}-1.5 \mathrm{Si}$ gas atomized powders.

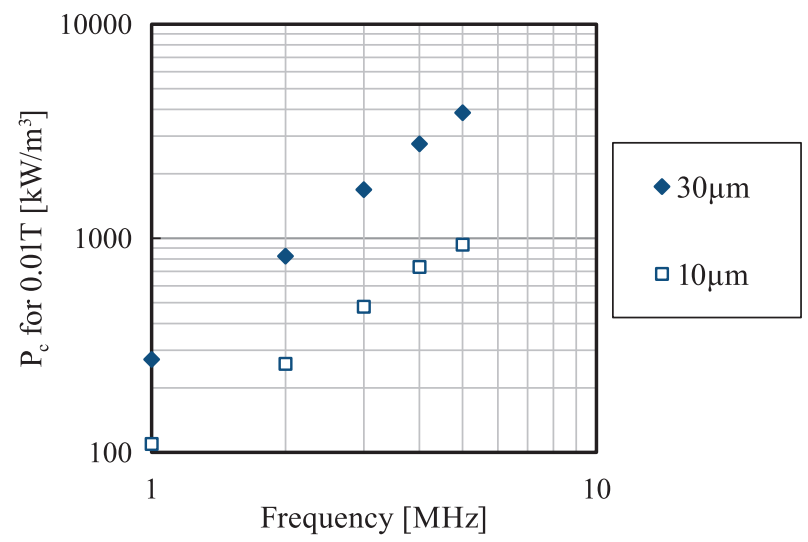

Fig. 7 Frequency characteristics of $\mathrm{P}_{c}$ for $48 \mathrm{Ni}-1.5 \mathrm{Si}$ gas atomized powders

$5 \mathrm{MHz}$ were no significant differences but $\mathrm{P}_{\mathrm{c}}$ at $5 \mathrm{MHz}$ for $0.01 \mathrm{~T}$ were drastically reduced by using finer powder.

The particle diameters of $\mathrm{Fe}-48 \mathrm{Ni}-1.5 \mathrm{Si}$ water atomized powders are shown in Table 6, and SEM images of each powder are shown in Fig. 8. The compaction pressures and the packing fractions of
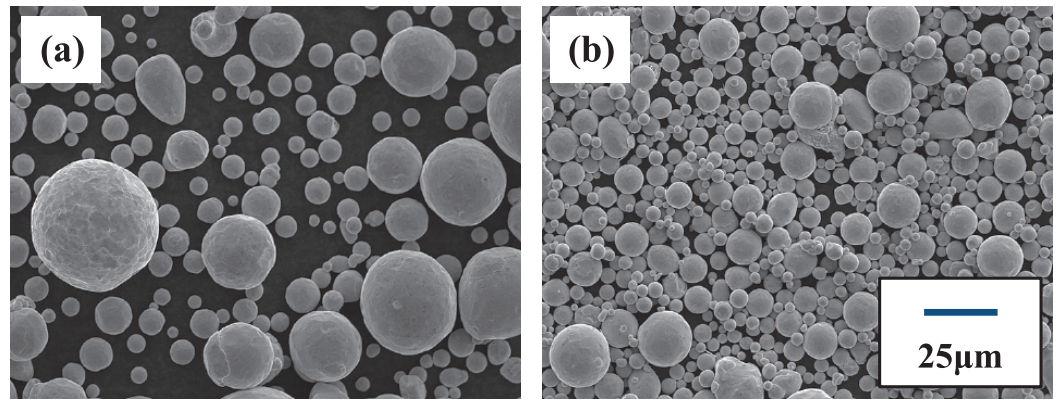

Fig. 5 SEM images of Fe-48Ni-1.5Si gas atomized powders: (a) $30 \mu \mathrm{m}$ and (b) $10 \mu \mathrm{m}$. 
Table 6 The particle diameters of Fe-48Ni-1.5Si water atomized powders.

\begin{tabular}{rccc}
\hline & $\mathrm{D}_{10}[\mu \mathrm{m}]$ & $\mathrm{D}_{50}[\mu \mathrm{m}]$ & $\mathrm{D}_{90}[\mu \mathrm{m}]$ \\
\hline $10 \mu \mathrm{m}$ & 4.4 & 10.1 & 18.6 \\
$9 \mu \mathrm{m}$ & 4.1 & 9.1 & 18.0 \\
$8 \mu \mathrm{m}$ & 3.8 & 8.0 & 14.9 \\
$7 \mu \mathrm{m}$ & 3.6 & 7.0 & 12.7 \\
$6 \mu \mathrm{m}$ & 3.0 & 5.9 & 10.7 \\
$5 \mu \mathrm{m}$ & 2.6 & 5.0 & 8.9 \\
$4 \mu \mathrm{m}$ & 1.8 & 4.0 & 6.3 \\
$3 \mu \mathrm{m}$ & 1.3 & 3.1 & 5.2 \\
\hline
\end{tabular}

Table 7 The compaction pressures and the packing fractions of toroidal cores for $\mathrm{Fe}-48 \mathrm{Ni}-1.5 \mathrm{Si}$ water atomized powders.

\begin{tabular}{ccc}
\hline & $\begin{array}{c}\text { Compaction pressure } \\
{[\mathrm{MPa}]}\end{array}$ & $\begin{array}{c}\text { Packing fraction } \\
{[\text { vol\%] }}\end{array}$ \\
\hline $10 \mu \mathrm{m}$ & 1225 & 77.4 \\
$9 \mu \mathrm{m}$ & 1225 & 77.0 \\
$8 \mu \mathrm{m}$ & 1225 & 77.1 \\
$7 \mu \mathrm{m}$ & 1274 & 77.5 \\
$6 \mu \mathrm{m}$ & 1274 & 77.4 \\
$5 \mu \mathrm{m}$ & 1323 & 77.1 \\
$4 \mu \mathrm{m}$ & 1421 & 77.0 \\
$3 \mu \mathrm{m}$ & 1421 & 76.6 \\
\hline
\end{tabular}

toroidal cores for water atomized powders were shown in Table 7. As results of the magnetic measurements, the frequency characteristics of $\mu_{\mathrm{e}}{ }^{\prime}$ and $\mathrm{P}_{\mathrm{c}}$ for each powder are shown in Fig. 9 and Fig. 10, respectively. And the effects of mean particle diameters of the powders on $\mu_{\mathrm{e}}{ }^{\prime}$ at $5 \mathrm{MHz}$ and $\mathrm{P}_{\mathrm{c}}$ at $5 \mathrm{MHz}$ for $0.01 \mathrm{~T}$ are shown in Fig. 11 and Fig. 12, respectively.

From these results, $\mu_{\mathrm{e}}$ ' slightly decreased but $\mathrm{P}_{\mathrm{c}}$ was gradually reduced with decreasing the mean particle diameter of powders.

3.3 Effect of heat treatment of the magnetic core

The effects of heat treatment temperature for $\mathrm{Fe}-48 \mathrm{Ni}-1.5 \mathrm{Si}$ water atomized powder on $\mu_{\mathrm{e}}{ }^{\prime}$ at $5 \mathrm{MHz}$ and $\mathrm{P}_{\mathrm{c}}$ at $5 \mathrm{MHz}$ for $0.01 \mathrm{~T}$ are shown in Fig. 13 and Fig. 14, respectively. $\mu_{\mathrm{e}}{ }^{\prime}$ was improved until $750{ }^{\circ} \mathrm{C}$ with increasing heat treatment temperature, but extremely worsened at $800{ }^{\circ} \mathrm{C}$ compared with other conditions. $\mathrm{P}_{\mathrm{c}}$ were no significant differences until $600{ }^{\circ} \mathrm{C}$, but worsened at over

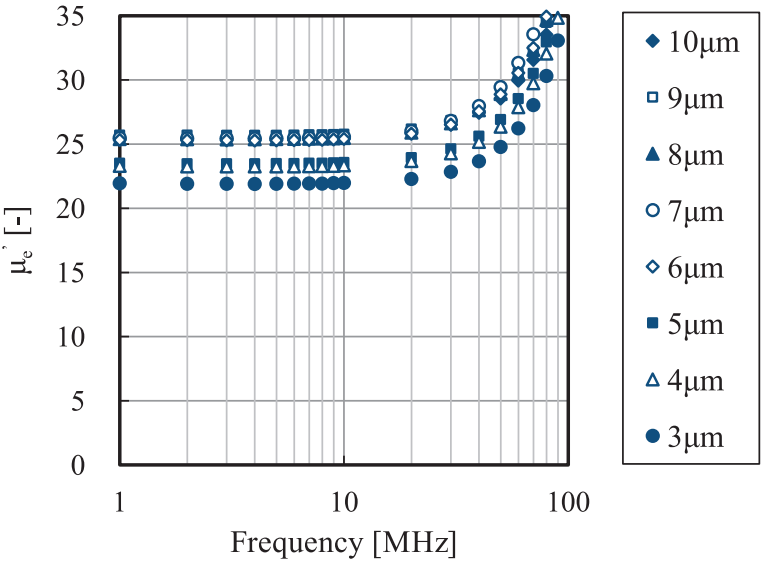

Fig. 9 Frequency characteristics of $\mu_{\mathrm{e}}{ }^{\prime}$ for $48 \mathrm{Ni}-1.5 \mathrm{Si}$ water atomized powders.

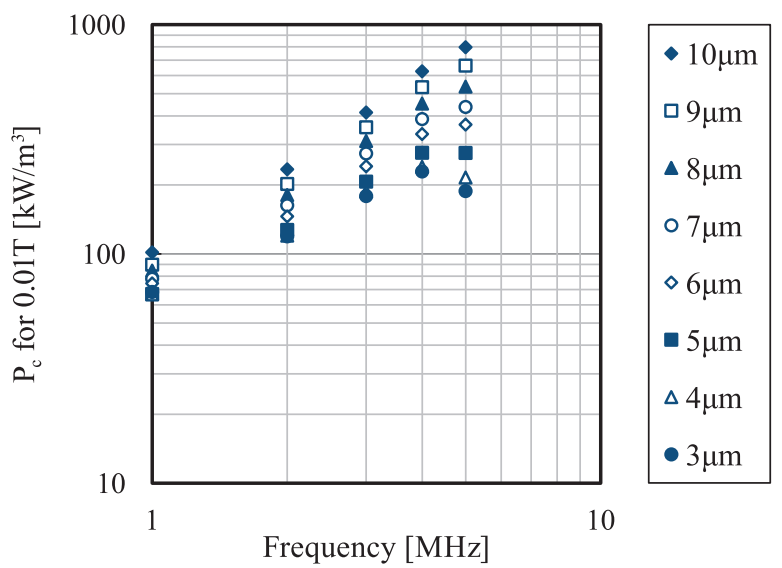

Fig. 10 Frequency characteristics of $\mathrm{P}_{\mathrm{c}}$ for $48 \mathrm{Ni}-1.5 \mathrm{Si}$ water atomized powders.

$700{ }^{\circ} \mathrm{C} . \mathrm{P}_{\mathrm{c}}$ at $5 \mathrm{MHz}$ for $0.01 \mathrm{~T}$ could not be measured at $800{ }^{\circ} \mathrm{C}$.

\section{Discussion}

$\mu_{\mathrm{e}}{ }^{\prime}$ was slightly decreased by $\mathrm{Si}$ addition. It was considered that Si behaved as impurity for ferromagnetic phase.

In Fig. 6, difference in the frequency characteristics of mean particle size were caused by skin depth. Skin depth $\mathrm{s}$ is given by equation $(2)^{5}$.
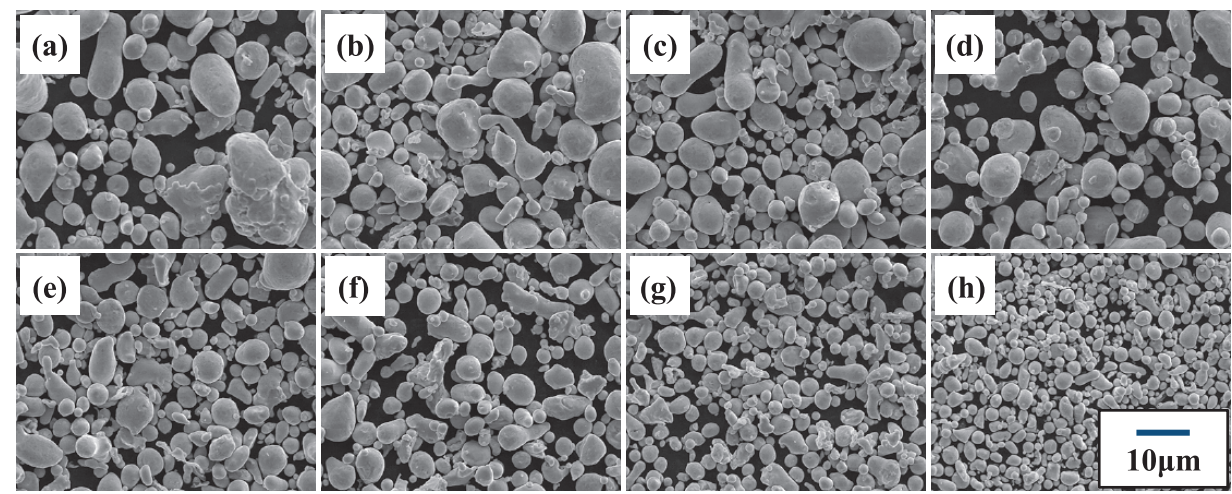

(h)

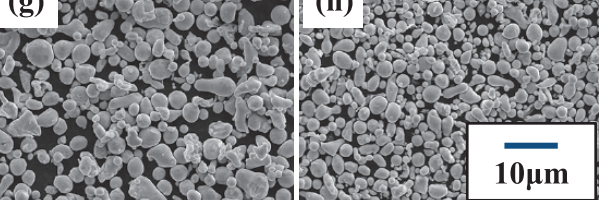

Fig. 8 SEM images of Fe-48Ni-1.5Si water atomized powders: (a) $10 \mu \mathrm{m}$, (b) $9 \mu \mathrm{m}$, (c) $8 \mu \mathrm{m}$, (d) $7 \mu \mathrm{m}$, (e) $6 \mu \mathrm{m}$, (f) $5 \mu \mathrm{m}$, (g) $4 \mu \mathrm{m}$ and (h) $3 \mu \mathrm{m}$. 


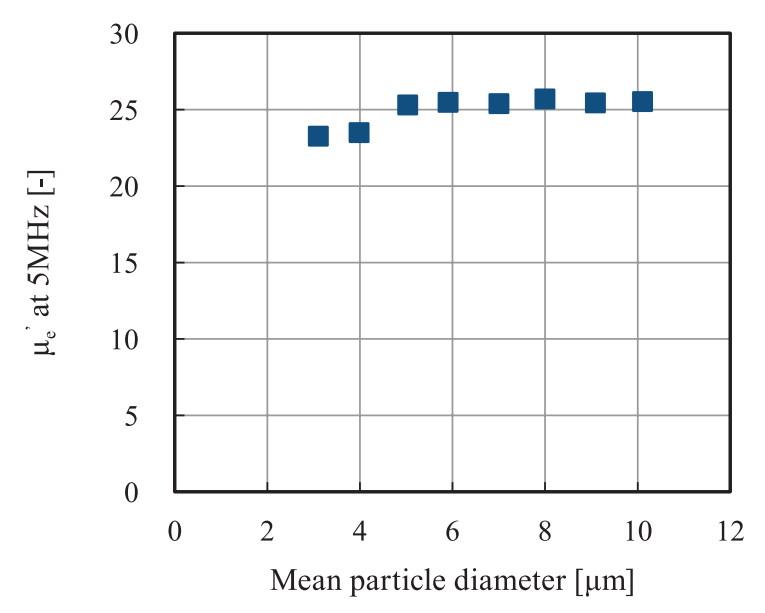

Fig. 11 Effect of mean particle diameter of $\mathrm{Fe}-48 \mathrm{Ni}-1.5 \mathrm{Si}$ water atomized powder on $\mu_{\mathrm{e}}^{\prime}$ at $5 \mathrm{MHz}$.

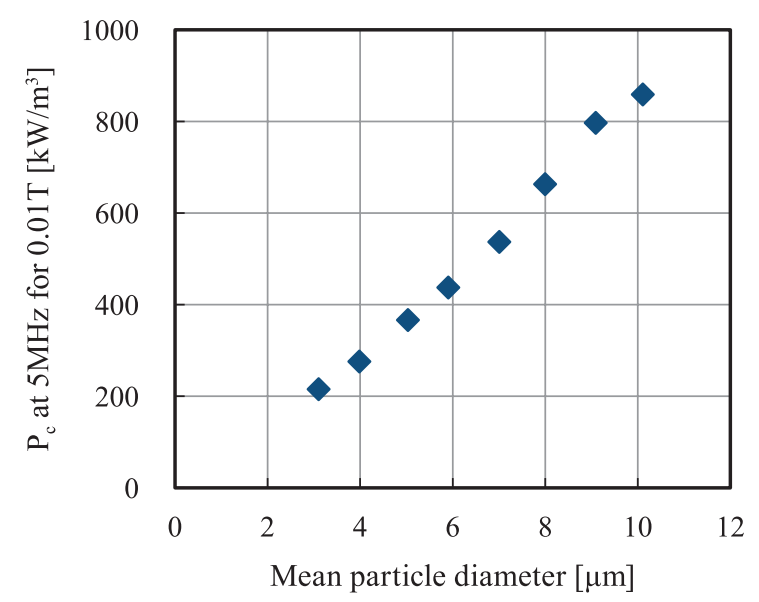

Fig. 12 Effect of mean particle diameter of Fe-48Ni-1.5Si water atomized powder on $\mathrm{P}_{\mathrm{c}}$ at $5 \mathrm{MHz}$ for $0.01 \mathrm{~T}$.

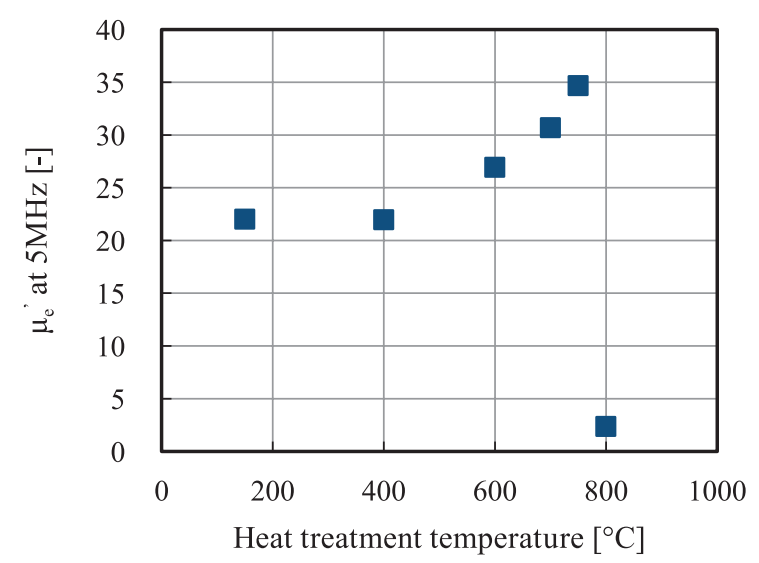

Fig. 13 Effect of heat treatment temperature for $\mathrm{Fe}-48 \mathrm{Ni}-1.5 \mathrm{Si}$ water atomized powder on $\mu_{\mathrm{e}}{ }^{\prime}$ at $5 \mathrm{MHz}$.

$$
\mathrm{s}=\sqrt{\frac{\rho}{\pi \cdot \mathrm{f} \cdot \mu_{\mathrm{r}} \cdot \mu_{0}}}
$$

where $\rho$ is electrical resistivity, $\mathrm{f}$ is frequency and $\mu_{\mathrm{r}}$ is relative permeability.

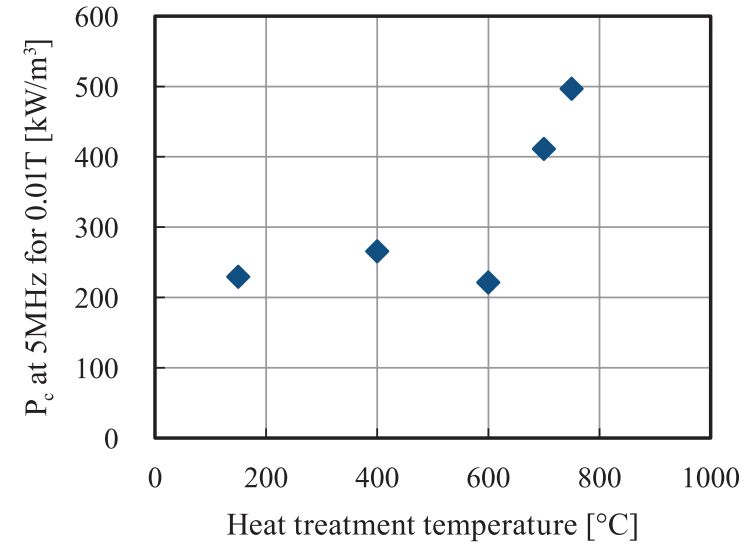

Fig. 14 Effect of heat treatment temperature for $\mathrm{Fe}-48 \mathrm{Ni}-1.5 \mathrm{Si}$ water atomized powder on $\mathrm{P}_{\mathrm{c}}$ at $5 \mathrm{MHz}$ for $0.01 \mathrm{~T}$.

In the past researches, electrical resistivity of $50 \mathrm{Ni}-\mathrm{Fe}$ was 40 $\times 10^{-8} \Omega \cdot \mathrm{m}$ and increased about $10.5 \times 10^{-8} \Omega \cdot \mathrm{m}$ by the addition of $1 \% \mathrm{Si}^{2}$. So, $\rho$ of $48 \mathrm{Ni}-1.5 \mathrm{Si}$ is about $55.8 \times 10^{-8} \Omega \cdot \mathrm{m}$. Skin depth at $20 \mathrm{MHz}$ calculated by equation (2) was $18.0 \mu \mathrm{m}$. Mean particle diameter of $30 \mu \mathrm{m}$ was larger than skin depth, but that of $10 \mu \mathrm{m}$ was smaller. Therefore it was considered that the frequency characteristics of $\mu_{\mathrm{e}}{ }^{\prime}$ were different.

Core loss $\mathrm{P}_{\mathrm{c}}$ is given by equation (3) ${ }^{6}$.

$$
\begin{aligned}
& P_{c}=P_{h}+P_{e} \\
& P_{c}=k_{h} \cdot B_{m}^{1.6} \times f+k_{e} \cdot B_{m}^{2} f^{2},
\end{aligned}
$$

where $\mathrm{P}_{\mathrm{h}}$ is hysteresis loss, $\mathrm{P}_{\mathrm{e}}$ is eddy current loss, $\mathrm{k}_{\mathrm{h}}$ is hysteresis loss coefficient, $\mathrm{B}_{\mathrm{m}}$ is magnetic flux density and $\mathrm{k}_{\mathrm{e}}$ is eddy current loss coefficient.

$\mathrm{P}_{\mathrm{h}}$ and $\mathrm{P}_{\mathrm{e}}$ separated from the results of Fig. 2 by equation (3) are shown in Fig. 15. These results show the eddy current loss is significantly influence on core loss in higher frequency range. So, we consider the reduction of eddy current loss is very important in high frequency range. The eddy current loss is given by equation $(4)^{6}$.

$$
\mathrm{P}_{\mathrm{e}}=\frac{\pi^{2} \cdot \mathrm{d}^{2} \cdot \mathrm{B}_{\mathrm{m}}^{2} \cdot \mathrm{f}^{2}}{\mathrm{C} \cdot \rho}
$$

where $\mathrm{d}$ is particle diameter and $\mathrm{C}$ is shape coefficient.

From the section 3.1 and 3.2 , core loss is improved by $\mathrm{Si}$ addition or using finer powder. In equation (4), magnetic flux density and frequency are determined by applications. From the point of view of materials, the eddy current loss depends on the particle diameter and the electrical resistivity. Comparison of the measurement results and the calculation values at $5 \mathrm{MHz}$ for $0.01 \mathrm{~T}$ with regards to $\mathrm{Si}$ addition and mean particle diameter are shown in Fig. 16 and Fig. 17, respectively. In Fig. 16 and Fig. 17, the calculation values were calculated from measurement result of the value for $0 \%$ in Si addition and $30 \mu \mathrm{m}$ in mean particle diameter by equation (4), respectively. From Fig. 16 and Fig. 17, the 


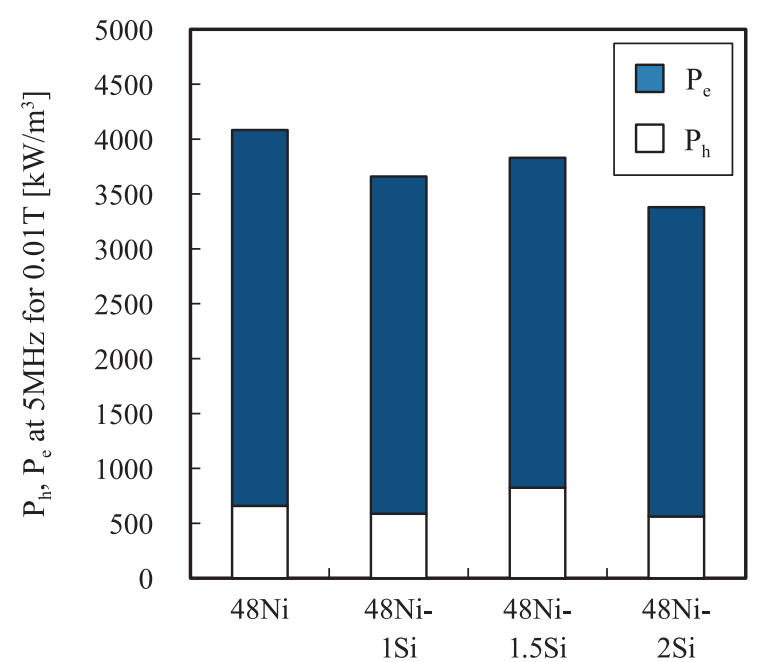

Fig. $15 \mathrm{P}_{\mathrm{h}}$ and $\mathrm{P}_{\mathrm{e}}$ at $5 \mathrm{MHz}$ for $0.01 \mathrm{~T}$ separated from the measurement results of Si addition.

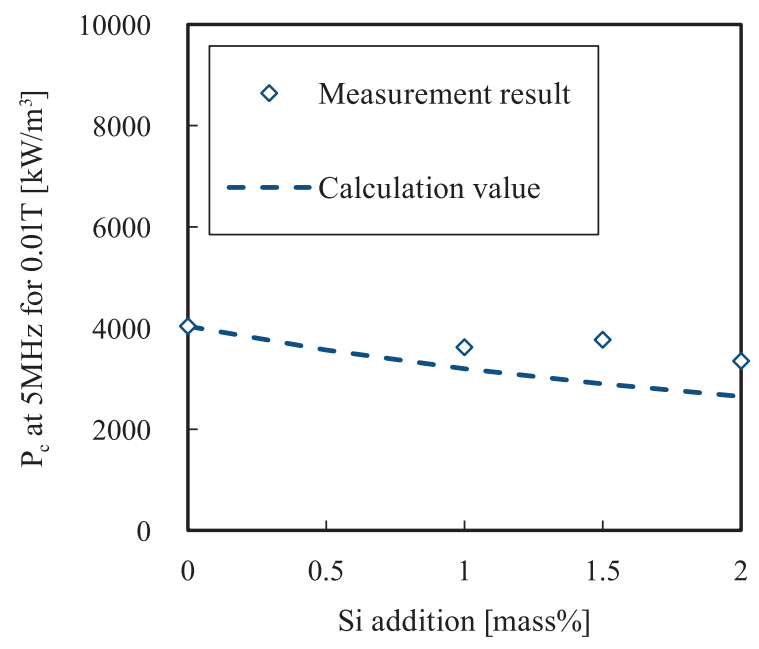

Fig. 16 Comparison of the measurement results and the calculation values at $5 \mathrm{MHz}$ for $0.01 \mathrm{~T}$ with regards to $\mathrm{Si}$ addition.

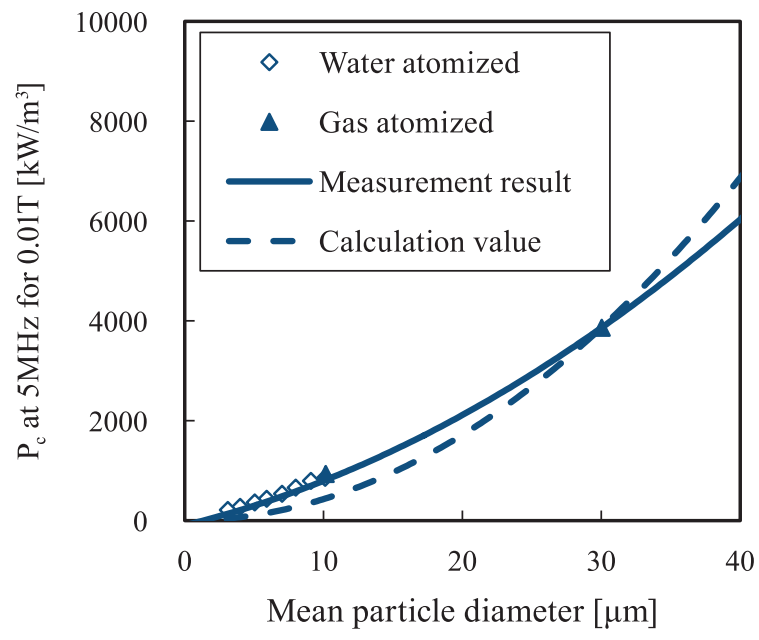

Fig. 17 Comparison of the measurement results and the calculation values at $5 \mathrm{MHz}$ for $0.01 \mathrm{~T}$ with regards to mean particle diameter. measurement results and the calculation values were not matched, but it was confirmed that $\mathrm{P}_{\mathrm{c}}$ decreased by increasing electrical resistivity and decreasing the mean particle diameter. Furthermore, the particle diameter had a greater effect on the core loss than electrical resistivity.

In Fig. 10, $\mathrm{P}_{\mathrm{c}}$ of $3 \sim 5 \mu \mathrm{m}$ in the mean particle diameters decreased at $5 \mathrm{MHz}$. From the results of the considerations, we concluded that measurements were carried out correctly. However, causes of these results remained unknown.

From the section 3.3, release of internal stress by heat treatment occurred to improve permeability of powder, therefore $\mu_{\mathrm{e}}{ }^{\prime}$ of core was improved. $\mu_{\mathrm{e}}{ }^{\prime}$ of the core heat-treated at $400{ }^{\circ} \mathrm{C}$ was no significant difference from resin hardening because the heat treatment temperature was not sufficient to obtain these effects. At the temperature of $800{ }^{\circ} \mathrm{C}$, it was considered that the insulation of silicone resin was destroyed by heat. The results of the core loss were no significant difference until $600{ }^{\circ} \mathrm{C}$ in heat treatment temperature. At the temperatures of 700 and $750{ }^{\circ} \mathrm{C}$, it was considered that the insulation of silicone resin was partly destroyed by heat and then interparticle eddy current loss was generated, therefore the core loss was worsened.

\section{Conclusion}

In this work, we investigated the effects of $\mathrm{Si}$ addition and the mean particle diameter on the magnetic properties in high frequency over $1 \mathrm{MHz}$. The results indicated the mean particle diameter affected the core loss in high frequency drastically.

In case of $3 \mu \mathrm{m}$ in the mean particle diameter of powder and $600{ }^{\circ} \mathrm{C}$ in the heat treatment temperature of core, we obtained excellent results that $\mu_{\mathrm{e}}{ }^{\prime}$ at $5 \mathrm{MHz}$ was 27 and $\mathrm{P}_{\mathrm{c}}$ at $5 \mathrm{MHz}$ for $0.01 \mathrm{~T}$ was $220 \mathrm{~kW} / \mathrm{m}^{3}$.

From these results, we found the availability of soft magnetic powders in high frequency over $3 \mathrm{MHz}$ for using inductors.

\section{References}

1) R. M. Bozorth: Ferromagnetism, Van Nostrand (1951) 102-134.

2) Y. Ichinose: "Influence of Si Additions on Magnetic Properties and the Refining Effect in Vacuum Melting of 50Ni-Fe Alloy", Trans. JIM, 9 (1968) 166-171.

3) M. Fukuda, K. Kume, Y. Matsushita, F. Kino: "Dependence of Permeability on Si Addition to Fe-Ni Alloy Soft Magnetic Powders in high frequency region”, Proceedings of the 2012 Powder Metallurgy World Congress \& Exhibition, H. Miura and A. Kawasaki ed., Yokohama, Japan Society of Powder and Powder Metallurgy, (2013) 15F-T14-3 (CD-ROM).

4) Keysight Technologies, "Solution for Measuring Permittivity/ Permeability with LCR Meters and Impedance Analyzers", Application Note 1369-1 (2015).

5) S. Chikazumi: Kyojiseitai no Butsuri, Shokabo (1959) 231-236.

6) R. M. Bozorth: Ferromagnetism, Van Nostrand (1951) 778-783. 